\title{
APOE E2 Carriers Showed Worse Associative Learning Than E3 Carriers in a Cognitively Normal Aging Han Chinese Population
}

Wei Li

Shanghai Jiao Tong University School of Medicine

Ling Yue

Shanghai Jiao Tong University School of Medicine

Xia Li

Shanghai Jiao Tong University School of Medicine

Shifu Xiao ( $\square$ xiaoshifu@msn.com )

Shanghai Jiao Tong University School of Medicine

\section{Research Article}

Keywords: APOE E2, cognitively normal aging, associative learning, Chinese

Posted Date: June 1st, 2021

DOI: https://doi.org/10.21203/rs.3.rs-504367/v1

License: (c) (i) This work is licensed under a Creative Commons Attribution 4.0 International License.

Read Full License 


\section{Abstract}

Background: Polymorphism in the APOE gene has been shown to be associated with cognitive function, however, the related studies are not consistent. To investigate the relationship between APOE gene polymorphism and cognitive function, we conducted the current cross-sectional study specifically to investigate the effect of different $A P O E$ genotypes on cognitive performance in normal elderly adults

Methods: A total of 156 older adults with normal cognitive function were enrolled in the current study. According to different genetic types, they were divided into three groups: 1) E2/2 or E2/3 (APOE E2); 2) E3/3 (APOE E3); and 3) E2/4, E3/4, or E4/4 (APOE E4). Then Montreal Cognitive Assessment (MoCA) and Neuropsychological Test Battery (NTB) were used to assess their global cognitive function and domainspecific cognitive function, respectively.

Results: The results of Kruskai-Wallis $\mathrm{H}$ test showed that the scores of associative learning in APOE E2 group were lower than that in E3 groups $(p<0.05)$, but there was no statistical difference $(p>0.05)$ in associative learning between E2 group and E4 group, and E3group and E4 group. Similarly, there was no difference $(p>0.05)$ in the global cognitive function among the three groups.

Conclusion: $A P O E \mathrm{E} 2$ is associated with decreased associative learning function than $A P O E \mathrm{E} 3$ in a cognitively normal aging Han Chinese population.

\section{Introduction}

Genetic variance might account for individual differences in adult cognitive function ${ }^{1}$. Apolipoprotein $\mathrm{E}$ $(A P O E)$, a gene implicated in the transport of cholesterol and other lipids between cellular structures ${ }^{2}$, has been experiencing as the largest contributor to genetic risk for late onset Alzheimer's disease $(A D)^{3}$. It is genetically associated with two single-nucleotide polymorphisms (SNPs) that mark three alleles $\varepsilon 4, \varepsilon 3$, and $\varepsilon 2^{4}$. And the $₫ 4$ allele has been demonstrated to increase associations between cerebral $A \beta$ level and cognitive functioning in adults with dementia and healthy older adults ${ }^{5,6}$. Although considerable research has been done on $\varepsilon 4, \varepsilon 2$ has been seriously neglected because of its low allele frequency. Previous studies suggest that possession of a $\varepsilon 2$ allele, prevalent in $15 \%$ of the population ${ }^{7}$, is associated with a lower risk of $A D$, less $A D$ neuropathology as well as a slower progression of vascular cognitive impairment ${ }^{8-10}$. However, a study ${ }^{11}$ shows that possession of an $\varepsilon 2$ allele is associated with poorer cognitive performance and more psychiatric symptoms in chronic, combat-related posttraumatic stress disorder (PTSD) subjects, while another study ${ }^{12}$ also suggests that carriers of the e2 allele shows performance disadvantages in sustained attention. What's more, some studies have even identified the $\varepsilon 2$ allele as a risk factor in dysbetalipoproteinemia ${ }^{13}$, cerebral small-vessel disease ${ }^{14}$, and aggressiveness of certain cancer ${ }^{15}$. Therefore, relevant research conclusions are not consistent.

Until now, only a few studies have been involved in the relationship between $A P O E$ gene polymorphism and cognitive function in Chinese normal cognitive elderly. For example, Zhen $\mathrm{J}^{16}$ et al find that $A P O E$ 
genotype might modify the risk for cognitive impairment in old age diabetes patients, and Su yy ${ }^{17}$ et al prove that $\varepsilon 2$ might as a protective factor in Chinese dialysis population since it might reduce the prevalence and of the onset age of depression. However, these above studies only focus on the general cognitive function of the subjects but neglect their specific cognitive areas, so we conducted this crosssection study to examine the relationship between the $A P O E \varepsilon 2$ allele and various cognitive fields (composed of global cognitive function and multiple domains of cognitive function) among the elderly with normal cognitive function in China

\section{Methods}

A total of 156 elderly people (male/female $=61 / 95$ ) with normal cognitive function were included in the study. Sampling methods and processes have been described in detail in our previous study ${ }^{18}$. All participants met the following criteria: Han Chinese, aged 60 and over;

2) normal cognitive ability; 3) without major medical abnormalities (e.g. cancer and infection); 4) without serious mental illness (e.g. schizophrenia, and dementia); 5) willing to cooperate. A standardized questionnaire was utilized to collect these participants' general information (for example, age and education), daily living habits (smoking and drinking) and medical conditions (diabetes and hypertension).What's more, a completion of physical examinations, MRI scans and laboratory tests were also obtained for each subject.

All participants gave written consent to participating in this study. And the study was approved by the Research Ethical Committee of the affiliated mental health center of Shanghai jiaotong university school of medicine.

\section{Clinical Assessment and Cognitive Assessment}

The Neuropsychological Test Battery [consists of Digit span ${ }^{19}$ (assess attention, working memory and executive function), Verbal fluency ${ }^{20}$ (measure language ability related to executive function), Auditory verbal learning test ${ }^{21}$ (assess learning ability, recognition memory and delayed free recall), Associative learning and visual identification test ${ }^{22}$ (assess visual attention and processing speed), Webster picture completion ${ }^{23}$ (evaluate executive function) and Webster block design ${ }^{24}$ (assess visuospatial and executive function)] and the Montreal Cognitive Assessment (MoCA $)^{25}$ were used as tools to assess their specific cognitive domains and global cognitive ability, respectively.

\section{APOE genotype and blood lipids}

Genomic DNA was extracted from peripheral blood (Morning fasting whole blood) by using a Blood Genomic DNA Extraction Kit (Qiagen NV, Venlo, the Netherlands). APOE genotype was determined by allele-specific polymerase chain reaction (PCR) methodology ${ }^{26}$. Then these 156 subjects were divided into three groups according to different genotypes, $A P O E \mathrm{E} 2(\varepsilon 2 / \varepsilon 2$ and $\varepsilon 2 / \varepsilon 3, \mathrm{n}=25), A P O E \mathrm{E} 3(\varepsilon 3 / \varepsilon 3$, 
$\mathrm{n}=106)$, and $A P O E \mathrm{E} 4(\varepsilon 2 / \varepsilon 4, \varepsilon 3 / \varepsilon 4$, and $\varepsilon 4 / \varepsilon 4, \mathrm{n}=25)$. Table1 presents the detailed distribution of $A P O E$ genotypes. In addition, all participants were also tested for plasma glucose, cholesterol, triglycerides, high density lipoprotein and low density lipoprotein.

\section{Data analysis}

Continuous variables were expressed as mean $\pm S D$ and categorical variables were expressed as frequencies (\%). One sample Kolmogorov-Smirrnov test was used to test whether the data conform to a normal distribution. Chi square test was utilized to compare categorical variables. One-way analysis of variance (ANOVA) Least-Significant Difference (LSD) was used to compare the differences among the $A P O E$ E2 group, APOE E 3 group, and $A P O E \mathrm{E} 4$ group (normal distribution data); while Kruskai-Wallis $\mathrm{H}$ test was used to compare data of non-normal distribution among three groups. Two-tailed tests were utilized in a significance level of $\mathrm{P}<0.05$ for all analyses. All statistical analyses were performed using SPSS 22.0 (IBM Corporation, Armonk, NY, USA).

\section{Results}

\section{Characteristic of subjects with different APOE genotypes}

Table 1 presents the characteristic of subjects with different APOE genotypes. There was no difference ( $p>0.05$ ) in education, age, BMI, gender, diabetes, hypertension, current smoking status, current drinking status, MoCA, Digit span, Immediate memory, Visual discrimination, Language fluency, Delayed memory, Wechsler mapping and Wechsler Block Map among the three groups. The results of Kruskai-Wallis $\mathrm{H}$ test (as the data did not conform to the normal distribution) showed that there were statistical differences $(\mathrm{p}<0.05)$ in Associative Learning among the three groups. Further comparisons revealed that the scores (6.240 \pm 3.163$)$ of Associative Learning in $A P O E$ E2 group were lower than those (8.433 \pm 3.924$)$ in $A P O E$ E3 group ( $p<0.05)$, while there was no significant difference $(p>0.05)$ between $A P O E$ E2 group and $A P O E$ E4 group, and between $A P O E \mathrm{E} 3$ and E4. Figure 1 and Table 2 show the results.

\section{Discussion}

In the present study, we investigated the effect of $A P O E$ gene polymorphism on cognitive performance in Chinese elderly with normal cognitive function. And found that E2 carriers had worse visual attention and processing speed ability than E3 carriers, while there was no difference between E2 and E4 carriers or E3 and E4 carriers.

There was no statistical difference in age, gender and education among the three groups. By using the Neuropsychological Test Battery and MoCA, we found that scores of association learning test in APOE E2 group (6.240 \pm 3.163$)$ were significantly lower than that $(8.433 \pm 3.924)$ in E 3 group. However, there was no statistical difference ( $p>0.05$ ) between the E2 group and E4 group (orE3 and E4 group). What's more, there was also no significant difference in global cognitive function among the three groups. 
Sinclair $\mathrm{LI}^{27}$ et al found that E2 carriers had slightly better episodic memory and executive functioning than E3 and E4 carriers in early to mid-adult, but Palmer Allred ND ${ }^{28}$ et al found E2 carriers had worse global cognitive function than E3 carriers. What's more, a large study ${ }^{29}$ (total $n=2013$ ) of APOE genotype and cognitive decline conduct in 2014 found no association between either E2 or E4 status and cognitive change in five separate tests, even when split by age group. So these relevant research conclusions were not consistent, and the discrepancy may be explained by ethnic differences.

There are several mechanisms may explain why $A P O E \mathrm{E} 2$ is associated with decreased associative learning function than $A P O E \mathrm{E} 3$. First, $A P O E \varepsilon 2$ status may influence the risk and progression of tauopathy ${ }^{30}$. Second, $A P O E \varepsilon 2$ may increase the likelihood of vascular disease and lead to cognitive decline in specific areas ${ }^{31}$. Third, under metabolic stress, $A P O E$ E2 homozygote may cause dysbetalipoproteinaemia in adults owing to impaired binding of remnant lipoproteins to heparan sulphate proteoglycans as well as the (low density lipoprotein) LDL receptor and related proteins ${ }^{32}$. Fourth, $A P O E$ E2 is correlated with increasing brain white matter hyperintensities $(\mathrm{WMHs})^{14}$, which is associated with neurologic decompression sickness, lower neurocognitive test performances as well as repetitive nonhypoxic hypobaric exposure 3334 .

We have to admit that there are some limitations in our research. First, this is only a cross-sectional study, and we cannot establish a causal link between $A P O E \mathrm{E} 2$ and associative learning function. Second, relatively small sample size reduces the reliability of research. Therefore, a large sample of longitudinal research is needed to further verify the above conclusion

\section{Conclusions}

In conclusion, $A P O E \mathrm{E} 2$ is associated with reduced associative learning function than $A P O E \mathrm{E} 3$ in healthy elderly. However, this conclusion needs to be verified by a larger sample of longitudinal study.

\section{Declarations}

\section{Ethics approval and consent to participate}

This study was conducted in accordance with the principles of Declaration of Helsinki, and approved by the Research Ethical Committee of the affiliated mental health center of Shanghai Jiaotong University School of Medicine. All participants had signed the informed consent written informed consent before the start of the study.

\section{Consent for publication}

Not applicable.

\section{Availability of data and materials}


The data base generated and/or analyzed during the current study are not publicly available but are available from the corresponding author on reasonable request.

\section{Competing interests}

The authors declare that they have no competing interests.

\section{Funding}

This work was supported by grants from the China Ministry of Science and Technology (2009BAl77B03), National Natural Science Foundation of China (number 81671402), Clinical research center project of Shanghai Mental Health Center (CRC2017ZD02), the National Key R\&D program of China (2017YFC1310501500), the Cultivation of Multidisciplinary interdisciplinary Project in Shanghai Jiao Tong University (YG2019QNA10),curriculum reform of Medical College of Shanghai Jiao Tong University and the Feixiang Program of Shanghai Mental Health Center(2020-FX-03).

\section{Authors' contributions}

"L.W . and L.Y wrote the main manuscript text and S.F. and L.X prepared figure 1."

\section{Acknowledgements}

Not applicable.

\section{References}

1. Bouchard TJ, Jr., McGue M. Familial studies of intelligence: a review. Science (New York, N.Y.). May 29 1981;212(4498):1055-1059.

2. Mahley RW. Apolipoprotein E: cholesterol transport protein with expanding role in cell biology. Science (New York, N. Y.). Apr 29 1988;240(4852):622-630.

3. Corder EH, Saunders AM, Strittmatter WJ, et al. Gene dose of apolipoprotein E type 4 allele and the risk of Alzheimer's disease in late onset families. Science (New York, N.Y.). Aug 13 1993;261(5123):921-923.

4. Rawle MJ, Davis D, Bendayan R, Wong A. Apolipoprotein-E (Apoe) epsilon4 and cognitive decline over the adult life course. Jan 10 2018;8(1):18.

5. Berr C, Dufouil C, Brousseau T, et al. Early effect of ApoE-epsilon 4 allele on cognitive results in a group of highly performing subjects: the EVA study. Etude sur le Vieillissement Arteriel. Neuroscience letters. Oct 25 1996;218(1):9-12.

6. Jonker C, Schmand B, Lindeboom J, Havekes LM, Launer LJ. Association between apolipoprotein E epsilon4 and the rate of cognitive decline in community-dwelling elderly individuals with and without dementia. Archives of neurology. Aug 1998;55(8):1065-1069. 
7. Raber J, Huang Y, Ashford JW. ApoE genotype accounts for the vast majority of AD risk and AD pathology. Neurobiology of aging. May-Jun 2004;25(5):641-650.

8. Blacker D, Lee H, Muzikansky A, et al. Neuropsychological measures in normal individuals that predict subsequent cognitive decline. Archives of neurology. Jun 2007;64(6):862-871.

9. Corder EH, Saunders AM, Risch NJ, et al. Protective effect of apolipoprotein E type 2 allele for late onset Alzheimer disease. Nature genetics. Jun 1994;7(2):180-184.

10. Berlau DJ, Corrada MM, Head E, Kawas $\mathrm{CH}$. APOE epsilon2 is associated with intact cognition but increased Alzheimer pathology in the oldest old. Neurology. Mar 3 2009;72(9):829-834.

11. Johnson LA, Zuloaga DG, Bidiman E, et al. ApoE2 Exaggerates PTSD-Related Behavioral, Cognitive, and Neuroendocrine Alterations. Neuropsychopharmacology : official publication of the American College of Neuropsychopharmacology. Sep 2015;40(10):2443-2453.

12. Lancaster $\mathrm{C}$, Tabet N, Rusted J. The APOE paradox: do attentional control differences in midadulthood reflect risk of late-life cognitive decline. Neurobiology of aging. Dec 2016;48:114-121.

13. Matsunaga A, Saito T. Apolipoprotein E mutations: a comparison between lipoprotein glomerulopathy and type III hyperlipoproteinemia. Clinical and experimental nephrology. Apr 2014;18(2):220-224.

14. Schilling S, DeStefano AL, Sachdev PS, et al. APOE genotype and MRI markers of cerebrovascular disease: systematic review and meta-analysis. Neurology. Jul 16 2013;81(3):292-300.

15. Ifere GO, Desmond R, Demark-Wahnefried W, Nagy TR. Apolipoprotein E gene polymorphism influences aggressive behavior in prostate cancer cells by deregulating cholesterol homeostasis. International journal of oncology. Oct 2013;43(4):1002-1010.

16. Zhen J, Lin T, Huang X, et al. Association of ApoE Genetic Polymorphism and Type 2 Diabetes with Cognition in Non-Demented Aging Chinese Adults: A Community Based Cross-Sectional Study. Aging and disease. Jun 2018;9(3):346-357.

17. Su YY, Zhang YF, Yang S, et al. Frequencies of apolipoprotein E alleles in depressed patients undergoing hemodialysis--a case-control study. Renal failure. Jun 2015;37(5):804-809.

18. Xiao S, Li J, Tang M, et al. Methodology of China's national study on the evaluation, early recognition, and treatment of psychological problems in the elderly: the China Longitudinal Aging Study (CLAS). Shanghai archives of psychiatry. Apr 2013;25(2):91-98.

19. Woods DL, Kishiyamaa MM, Lund EW, et al. Improving digit span assessment of short-term verbal memory. Journal of clinical and experimental neuropsychology. Jan 2011;33(1):101-111.

20. de Paula JJ, Paiva GCC, Costa DS. Use of a modified version of the switching verbal fluency test for the assessment of cognitive flexibility. Dementia \& neuropsychologia. Jul-Sep 2015;9(3):258-264.

21. Loring DW, Goldstein FC, Chen C, et al. False-Positive Error Rates for Reliable Digit Span and Auditory Verbal Learning Test Performance Validity Measures in Amnestic Mild Cognitive Impairment and Early Alzheimer Disease. Archives of clinical neuropsychology : the official journal of the National Academy of Neuropsychologists. Jun 2016;31(4):313-331. 
22. Li W, Qiu Q, Sun L, Li X, Xiao S. Short-term adverse effects of the apolipoprotein E epsilon4 allele over language function and executive function in healthy older adults. Neuropsychiatric disease and treatment. 2019;15:1855-1861.

23. Bhattacharya B, Marwaha RK, Malhotra S, Pershad D. Intellectual functions in childhood malignant disorders. Indian pediatrics. Aug 1995;32(8):869-875.

24. Gao Y, Xiao Y, Miao R, et al. The characteristic of cognitive function in Type 2 diabetes mellitus. Diabetes research and clinical practice. Aug 2015;109(2):299-305.

25. O'Driscoll C, Shaikh M. Cross-Cultural Applicability of the Montreal Cognitive Assessment (MoCA): A Systematic Review. Journal of Alzheimer's disease : JAD. 2017;58(3):789-801.

26. Donohoe GG, Salomaki A, Lehtimaki T, Pulkki K, Kairisto V. Rapid identification of apolipoprotein E genotypes by multiplex amplification refractory mutation system PCR and capillary gel electrophoresis. Clinical chemistry. Jan 1999;45(1):143-146.

27. Sinclair LI, Pleydell-Pearce CW, Day INM. Possible positive effect of the APOE epsilon2 allele on cognition in early to mid-adult life. Neurobiology of learning and memory. Dec 2017;146:37-46.

28. Palmer Allred ND, Raffield LM, Hardy JC, et al. APOE Genotypes Associate With Cognitive Performance but Not Cerebral Structure: Diabetes Heart Study MIND. Diabetes care. Dec 2016;39(12):2225-2231.

29. Bunce D, Bielak AA, Anstey KJ, Cherbuin N, Batterham PJ, Easteal S. APOE genotype and cognitive change in young, middle-aged, and older adults living in the community. The journals of gerontology. Series A, Biological sciences and medical sciences. Apr 2014;69(4):379-386.

30. Zhao N, Liu CC, Van Ingelgom AJ, et al. APOE epsilon2 is associated with increased tau pathology in primary tauopathy. Oct 22 2018;9(1):4388.

31. Wolters FJ, Yang Q, Biggs ML, Jakobsdottir J, Li S. The impact of APOE genotype on survival: Results of 38,537 participants from six population-based cohorts (E2-CHARGE). 2019;14(7):e0219668.

32. Marais AD. Apolipoprotein E in lipoprotein metabolism, health and cardiovascular disease. Pathology. Feb 2019;51(2):165-176.

33. McGuire SA, Sherman PM, Brown AC, et al. Hyperintense white matter lesions in 50 high-altitude pilots with neurologic decompression sickness. Aviation, space, and environmental medicine. Dec 2012;83(12):1117-1122.

34. Hellmann-Regen J, Hinkelmann K, Regen F, McGuire SA, Antonio S. White matter hyperintensities on MRI in high-altitude U-2 pilots. Neurology. Mar 25 2014;82(12):1102-1103.

\section{Tables}

Table1. Characteristics of subjects with different APOE groups 


\begin{tabular}{|llllll|}
\hline Characteristics & $\begin{array}{l}\text { APOE E2 } \\
(\mathrm{n}=25)\end{array}$ & $\begin{array}{l}\text { APOE E3 } \\
(\mathrm{n}=106)\end{array}$ & $\begin{array}{l}\text { APOE E4 } \\
(\mathrm{n}=25)\end{array}$ & $\mathrm{F}$ & $\mathrm{P}$ \\
\hline Age, $\mathrm{y}$ & $70.40 \pm 8.067$ & $70.01 \pm 7.786$ & $68.56 \pm 6.436$ & 0.445 & 0.642 \\
\hline Education, $\mathrm{y}$ & $8.52 \pm 4.445$ & $9.85 \pm 4.124$ & $10.68 \pm 2.673$ & 1.901 & 0.153 \\
\hline BMl, Kg/m ${ }^{2}$ & $24.22 \pm 3.037$ & $24.09 \pm 3.448$ & $24.35 \pm 3.504$ & 0.068 & 0.934 \\
\hline Male,n (\%) & $11(7.1)$ & $40(37.7)$ & $10(40.0)$ & 0.169 & 0.845 \\
\hline Hypertension, $\mathrm{n}(\%)$ & $14(56.0)$ & $53(50.0)$ & $12(48.0)$ & 0.184 & 0.832 \\
\hline Diabetes, $\mathrm{n}(\%)$ & $2(8.0)$ & $10(9.4)$ & $3(12.0)$ & 0.119 & 0.888 \\
\hline Smoker, $\mathrm{n}(\%)$ & $6(24.0)$ & $26(24.5)$ & $3(12.0)$ & 0.926 & 0.398 \\
\hline Drinker, $\mathrm{n}(\%)$ & $6(24.0)$ & $22(20.8)$ & $2(8.0)$ & 1.288 & 0.279 \\
\hline MoCA & $23.48 \pm 4.575$ & $25.39 \pm 3.643$ & $25.56 \pm 2.800$ & 2.923 & 0.057 \\
\hline Digit span & $13.56 \pm 4.144$ & $14.50 \pm 3.865$ & $14.28 \pm 3.273$ & 0.612 & 0.543 \\
\hline Immediate memory & $46.20 \pm 10.607$ & $41.60 \pm 11.601$ & $43.39 \pm 12.033$ & 1.672 & 0.191 \\
\hline Associative Learning & $6.240 \pm 3.163$ & $8.433 \pm 3.924$ & $7.646 \pm 3.746$ & 3.475 & $0.033 *$ \\
\hline Visual discrimination & $17.92 \pm 4.272$ & $17.41 \pm 3.590$ & $16.68 \pm 3.544$ & 0.588 & 0.557 \\
\hline Language fluency & $27.68 \pm 8.620$ & $28.97 \pm 7.924$ & $27.60 \pm 6.416$ & 0.488 & 0.615 \\
\hline Delayed memory & $22.40 \pm 9.574$ & $21.50 \pm 8.674$ & $22.32 \pm 8.778$ & 0.159 & 0.853 \\
\hline Wechsler mapping & $10.32 \pm 4.120$ & $10.90 \pm 3.713$ & $10.80 \pm 3.764$ & 0.234 & 0.791 \\
\hline Wechsler Block Map & $28.83 \pm 8.499$ & $28.64 \pm 8.597$ & $29.92 \pm 6.819$ & 0.240 & 0.787 \\
\hline
\end{tabular}

Note: Three groups were divided according to APOE genotypes: e2/2 or e2/3 (APOE e2); e3/3 (APOE e3); and e2/4, e3/4, or e4/4 (APOE e4). * means p< 0.05; Abbreviations: BMl, body mass index; MoCA, Montreal Cognitive Assessment

Table 2. Multiple comparisons among three groups 


\begin{tabular}{|lllllll|}
\hline Variables & Group 1 & Group 2 & $\begin{array}{l}\text { mean } \\
\text { deviation }\end{array}$ & $\begin{array}{l}\text { Standard } \\
\text { error }\end{array}$ & $\mathrm{p}$ & $95 \% \mathrm{Cl}$ \\
$\begin{array}{l}\text { Associative } \\
\text { Learning }\end{array}$ & $\begin{array}{l}\text { APOE } \\
\text { E2 }\end{array}$ & $\begin{array}{l}\text { APOE } \\
\text { E3 }\end{array}$ & -2.193 & 0.843 & $0.010^{*}$ & $-3.86 \sim-0.53$ \\
\cline { 2 - 7 } & $\begin{array}{l}\text { APOE } \\
\text { E4 }\end{array}$ & -1.406 & 1.082 & 0.196 & $-3.54 \sim-0.73$ \\
& \begin{tabular}{llllll|} 
APOE \\
E3
\end{tabular} & $\begin{array}{l}\text { E4 } \\
\text { EPOE }\end{array}$ & 0.787 & 0.857 & 0.360 & $-0.91 \sim 2.48$ \\
\hline
\end{tabular}

Figures

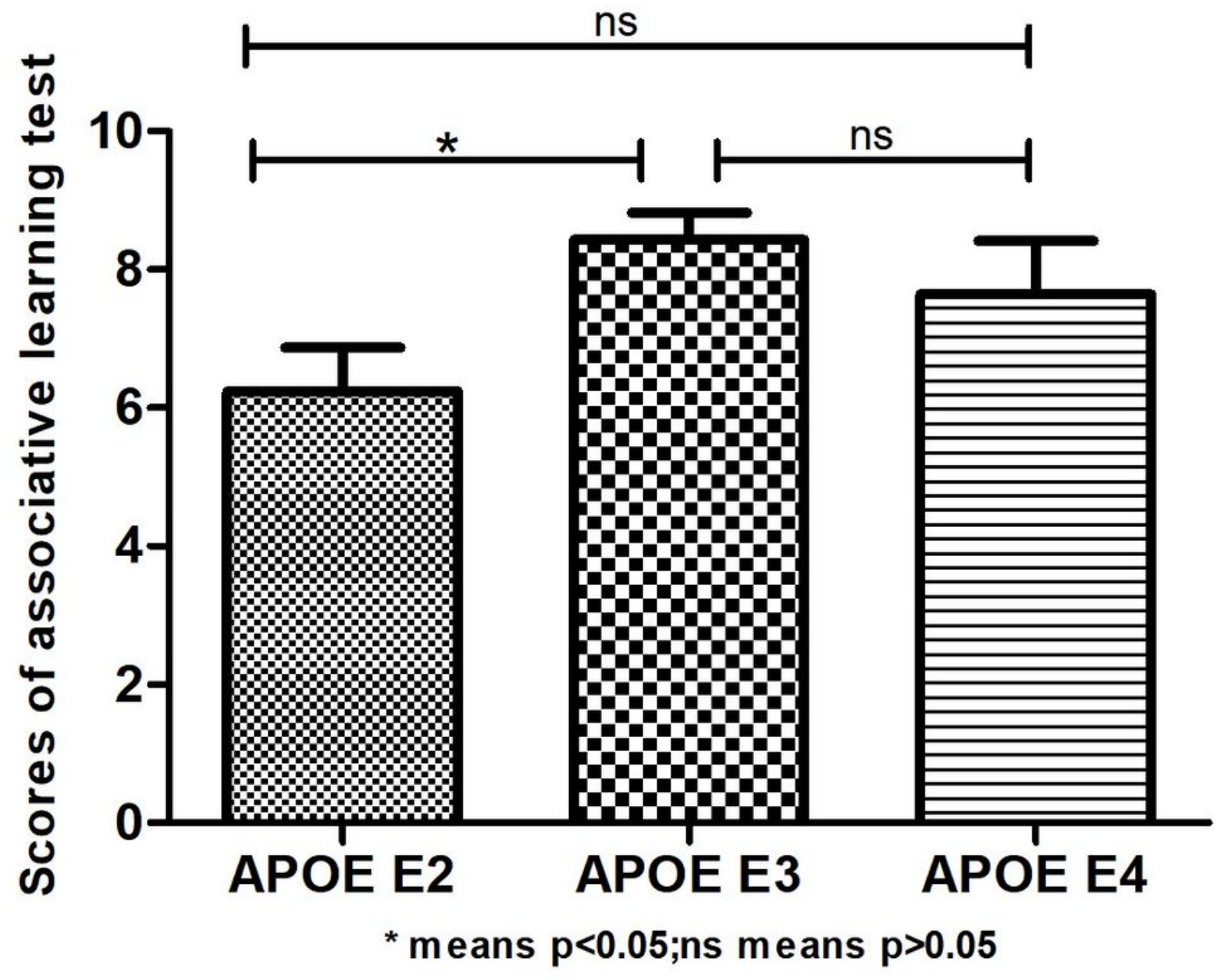

Figure 1 
Further comparisons revealed that the scores $(6.240 \pm 3.163)$ of Associative Learning in APOE E2 group were lower than those $(8.433 \pm 3.924)$ in APOE E3 group $(p<0.05)$, while there was no significant difference ( $p>0.05)$ between APOE E2 group and APOE E4 group, and between APOE E3 and E4. 